\title{
High-temperature crack growth in a Ni-base superalloy during sustained load
}

\author{
Magnus Hörnqvist ${ }^{\mathrm{a}, \mathrm{b}, 1}$, Leif Viskari ${ }^{\mathrm{a}, 2}$, Katie L. Moore ${ }^{\mathrm{c}}$ and Krystyna Stiller $^{\mathrm{a}}$ \\ ${ }^{a}$ Department of Applied Physics, Chalmers University of Technology, SE-41296, Göteborg, Sweden \\ ${ }^{\mathrm{b}}$ GKN Aerospace Engine Systems, SE-46181, Trollhättan, Sweden \\ ${ }^{\mathrm{c}}$ Department of Materials, University of Oxford, Oxford OX1 3PH, UK
}

\begin{abstract}
The high-temperature sustained load crack growth behaviour of a Ni-base superalloy was investigated using a combination of mechanical testing in controlled atmosphere, fractographical and microanalytical investigations, and finite element modelling. The results show that the local crack front geometry is un-even on two scales: jaggedness on the scale of $100 \mu \mathrm{m}$ was observed in all specimens, whereas mm-scale waviness could occasionally be observed. The jaggedness can be explained by a percolation-type crack growth along weaker grain boundaries, whereas the large-scale waviness is presumably due to larger regions of the material having specific grain texture with high crack growth resistance. The un-even crack front is shown to potentially have considerable effects on the loading conditions at the crack tip, whereas ligaments of un-cracked material in the crack wake are deemed to have less effect on the crack tip loading due to their low area fraction. The ligaments fail intergranularly in the wake as the crack grows in the present case, as opposed to by creep fracture as previously proposed. Finally, the plastically deformed regions about the crack and crack tip are shown not to exhibit any elevated oxygen levels, implying that the damage in these regions is purely mechanical.
\end{abstract}

Keywords: Superalloy, grain boundaries, mechanical properties, sustained load crack growth.

\section{Introduction}

Ni-base superalloys are well documented to exhibit time-dependent intergranular crack growth when subjected to sustained mechanical load at high temperatures in oxygen rich environments [1-8]. Several extensive summaries on this topic have recently been compiled [9-11]. The most prominent mechanisms currently proposed are strain-assisted grain boundary oxidation (SAGBO) [12] and dynamic embrittlement (DE) [4]. The concept of DE is based on the reduction in cohesive strength of grain boundaries, resulting from stress-driven diffusion of an embrittling species into the boundary.

\footnotetext{
${ }^{1}$ Corresponding author: magnus.hornqvist@chalmers.se

${ }^{2}$ Present address: AB SKF, SE-41550 Göteborg, Sweden
} 
The theoretical treatment of DE is today rather well developed [9], and the phenomenon is often invoked as an explanation to elemental embrittlement caused by both internal and external species. SAGBO, on the other hand, is a result of the formation of an intergranular oxide that cracks under the applied load. Some recent results have indicated that SAGBO, occurring on micron- or sub-micron scale, may indeed be a viable contributor to the environmental cracking of Ni-base superalloys [13, 14], leading to the development of an emerging theoretical model [15]. In this paper, the term sustained load crack growth (SLCG) is used as an unbiased expression.

Time dependent cracking generally occurs by (quasi-)brittle intergranular propagation. Bika et al. [16] reported that the crack front during SLCG in a sulphur-embrittled steel was jagged, with ligaments of un-cracked material in the wake of the main crack front. This was also later observed in an Ni-base superalloy in the work of Pfaendtner et al. [4] where it was proposed that the varying resistance to cracking due to grain boundary structure was the reason. The more susceptible grain boundaries will crack, leading to a locally propagating crack front between the more resistant boundaries. These resistant boundaries are then fully surrounded by the crack during the advancement of the crack front, and are left as ligaments in the wake. The ligaments and the lagging parts of the crack front were proposed to carry much of the applied load, while undergoing power-law creep due to the high stresses and temperatures [4]. Thus, the susceptible boundaries at the leading part of the crack will crack more slowly as the local stress intensities are lowered by the ligaments.

In accordance with this idea, it has been shown that grain boundary engineering by means of thermomechanical processing could be used to decrease the SCLG rate through introduction of an increased fraction of resistant grain boundaries $[17,18]$. The slower crack growth was accompanied by an increase in the area fraction of ligaments in the crack wake. This effect was mainly attributed to the occurrence of special $\Sigma 3$ boundaries [19, 20], which have been shown to provide much more resistance to crack growth than random high-angle boundaries or other special boundaries ( $\Sigma 19$ and $\Sigma 31)$ [19]. The $\Sigma 3$ boundaries were, however, not fully immune to cracking, but required significantly higher stress intensity factors to initiate the propagation and therefore the total crack growth rate was lower. The effects of local crack front geometry and remaining ligaments have also recently become important from a life prediction perspective, as models are being developed based on the existence of a "damaged zone" where such features are implicitly controlling the crack growth rate [21-23].

In another aspect, although SLCG is largely considered brittle, deformation ahead of the crack and in the crack flank has been reported $[7,24]$. Studies of the correlation between deformation and oxygen/oxidation for the considered conditions are scarce, although previous work on the interplay between slip bands and grain boundaries during SLCG is available [25]. However, such correlations have been shown to exist for stress corrosion cracking (SCC) in austenitic alloys [26, 27] using 
modern analysis methods. Recent findings by the authors on SLCG $[14,24]$ show that there are strong generic similarities between SCC and SLCG, although SCC concerns lower temperatures, far longer exposure times and water-bearing environments. The above clearly condone studies of oxygen in relation to plastic deformation and the "damaged zone" concept also for SLCG.

In this work we study the high-temperature SLCG in a Ni-base superalloy in order to highlight some additional aspects of environmentally assisted cracking. The investigation was performed on the Nibase superalloy Allvac 718Plus, which was heat treated to remove grain boundary precipitates in order to emphasize the environmental effects. It will be shown here that there is no observable oxygen diffusion ahead of the crack tip, or in the plastically deformed regions around the crack. The ligaments observed in the crack wake, have a minor effect on the crack tip loading in the present case due to their low number. They subsequently fracture by brittle oxygen induced failure as the stresses in the ligaments increase during crack growth, rather than through creep as have been previously proposed. On the other hand, geometric variations along the crack front resulting from the crack growth process will be shown to potentially have large influence on the local loading situation at different parts of the crack. This has not been considered in previous studies of sustained load or dwell-fatigue crack growth, and further adds to the complexity of the dynamic environmental embrittlement phenomenon.

\section{Experimental}

\subsection{Materials and heat treatment}

The material used in the investigation was the Ni-base superalloy Allvac 718Plus (wrought bar). The composition (in at. \%) is: $51.5 \mathrm{Ni}, 19.8 \mathrm{Cr}, 9.9 \mathrm{Fe}, 8.8 \mathrm{Co}, 3.4 \mathrm{Nb}, 3.1 \mathrm{Al}, 1.6 \mathrm{Mo}, 0.9 \mathrm{Ti}, 0.32 \mathrm{~W}$, $0.27 \mathrm{~B}, 0.12 \mathrm{Si}, 0.10 \mathrm{C}, 0.05 \mathrm{Mn}, 0.01 \mathrm{P},<0.01 \mathrm{~S}$. In order to simplify the oxygen interaction at the grain boundaries the alloy was heat treated to produce grain boundaries free of $\delta$ or $\eta$ phase precipitates. Such condition has been found to be more susceptible to dwell-time crack growth [8]. To achieve this the following heat treatment was performed: $1040{ }^{\circ} \mathrm{C} / 1 \mathrm{~h}(\mathrm{WQ})+788^{\circ} \mathrm{C} / 8 \mathrm{~h}(\mathrm{FC})+704$ ${ }^{\circ} \mathrm{C} / 8 \mathrm{~h}$ (FC), where WQ and FC refers to water quenching and furnace cooling, respectively. The first step dissolves the grain boundary phases along with existing hardening precipitates, whereas the subsequent steps correspond to the standard ageing treatment. Figure 1 shows the as heat-treated microstructure, with no grain boundary phases but with annealing twins and occasional $\mathrm{Nb}$ and $\mathrm{Ti}$ primary carbides. The hardness was measured to $429 \mathrm{HV} 10 \mathrm{~kg}$, which is in line with what is expected of Allvac 718Plus in the age-hardened condition.

\subsection{Mechanical testing}

Single-edge notched (SEN) mechanical testing specimens were machined to the geometry shown in Figure 2(a). A rectangular specimen waist cross-section of $8 \times 3 \mathrm{~mm}$ was used where a $0.2 \mathrm{~mm}$ deep through-thickness notch was produced on one of the $3 \mathrm{~mm}$ sides using electric discharge machining 
(EDM). Mechanical testing was performed using a MTS model 661 hydraulic rig with a custom designed environmental chamber, shown in Figure 2(b). The chamber allowed a controlled environment to be maintained while performing direct current potential drop (DCPD) monitoring of crack growth and induction heating of the specimen.

The specimens were pre-cracked in two stages, first at room temperature (RT) and then at $700{ }^{\circ} \mathrm{C}$, as shown schematically in Figure 2(c). The pre-crack load sequence was designed such that the size of the plastic zone at the crack tip would have minimal influence on the high temperature sustained load cycle. Thus, pre-crack loads ( $10 \mathrm{~Hz}$ triangular waveform with a load ratio $R=0.05$ ) were reduced incrementally to yield a final pre-crack plastic zone of similar size as for the start of the sustained load testing. Using this approach, pre-cracks were first grown at RT to an approximate length of $2.5 \mathrm{~mm}$ (step 1 in Figure 2(c)) and then additionally around $0.5 \mathrm{~mm}$ at $700{ }^{\circ} \mathrm{C}$ (step 3).

Following pre-cracking two different load sequences, referred to as Type 1 and Type 2, were applied. For both test types a single $600 \mathrm{~s}$ sustained load was applied at $700{ }^{\circ} \mathrm{C}$ using a load of $3 \mathrm{kN}$ (125 Mpa nominal stress) in a controlled environment of ${ }^{16} \mathrm{O}_{2}$ and ${ }^{18} \mathrm{O}_{2}$ at $1: 1$ volume ratio (step 4). Upon termination of the sustained load, the environment was immediately changed from the oxygen mix to forced convection cooling in Ar while at the same time turning off the induction heating and releasing the mechanical load to zero (step 5). The sample temperature was registered $<500{ }^{\circ} \mathrm{C}$ within $15 \mathrm{~s}$ and approximations by finite element calculation showed that the difference between surface mounted temperature probes and the sample interior is negligible during cooling. The cooling procedure is therefore considered to yield a nearly quenched state of the sample with regard to oxidation. For Type 1 samples no further steps were performed. For Type 2 samples an additional sequence (step 6) of 10 $\mathrm{Hz}$ cyclic loading was performed in Ar at room temperature following the sustained load. Details of each step are presented in Table 1. In total four specimens were tested, two of each type. These are referred to as specimens $1 \mathrm{~A}, 1 \mathrm{~B}, 2 \mathrm{~A}$ and $2 \mathrm{~B}$, where the digit indicates test type and the letter is the specimen identification. For specimen $2 \mathrm{~B}$, the equipment failed to record the PD signal during the sustained load period, which made it impossible to extract crack lengths for this specimen. The samples were analysed using high-resolution secondary ion mass spectroscopy (SIMS) and atom probe tomography (APT) techniques, which allow distinction of different isotopes and hence the distinction between oxygen from interactions during the sustained load in ${ }^{18} \mathrm{O}$-rich atmosphere and that from e.g. sample preparation and storage (which would be dominantly ${ }^{16} \mathrm{O}$ ).

A control specimen was used to evaluate the environment in the chamber. The same load and temperature sequence was used as for Type 1 specimens, however, the environment was changed from ambient air to flushing with $\operatorname{Ar}\left(>500 \mathrm{ml} \mathrm{s}^{-1}\right)$ for a duration of $180 \mathrm{~s}$ during the sustained load 
sequence. This immediately reduced the nominal crack growth rate approximately by half and indicates that a far less oxygen-rich atmosphere is obtained when flushing the chamber with Ar. Once the Ar-flushing was terminated, the crack growth rate immediately returned to a rate very similar to that prior to introducing Ar. This shows that the forced convection cooling in Ar (step 5) provides the intended more inert environment, and that no significant delay effects occurred upon changing between air and Ar.

\subsection{Analysis methods}

Scanning electron microscopy (SEM) studies were performed using FEI Quanta 200 and Zeiss Ultra 55 field-emission gun (FEG) instruments. Deformation in cross sections was studied by backscattered electron (BSE) imaging, where the channelling contrast provides information about the conditions of slip and local plasticity [28]. Samples for cross-sectional analyses were mechanically polished to 0.05 $\mu \mathrm{m}$ colloidal silica finish. Fracture surfaces were investigated in secondary electron (SE) mode, using an in-lens detector.

A CAMECA NanoSIMS 50 was used to study the oxygen distribution in and near the cracks with a lateral resolution of $<100 \mathrm{~nm}$ and oxygen detection capability down to ppm-level. A $16 \mathrm{keV} \mathrm{Cs}{ }^{+}$ primary ion beam was used with a probe current of $0.4-0.5 \mathrm{pA}$ and $10 \mathrm{~ms}$ dwell time per pixel (256x256 pixels). The detector positioning for ${ }^{18} \mathrm{O}^{-}$was calibrated using a sample with a known high concentration of the isotope. The same polished crack cross-sections used for SEM analyses were analysed.

APT was applied to study the microstructure and chemistry in the plastically deformed regions with near-atomic resolution, producing quantitative compositional information while the SIMS results shown in this work are regarded as qualitative. An Imago LEAP 3000X HR was used in laser pulsing mode ( $0.5 \mathrm{~nJ}$ laser energy) at $100 \mathrm{kHz}$ pulse rate and $2 \%$ target evaporation rate. Reconstructions of acquisitions were performed using IVAS 3.4.3 software. Site-specific focussed ion beam (FIB) preparation of APT samples was performed using a FEI Strata 235 combined FIB-SEM as described in [24].

\section{Results}

\subsection{Sustained load cracking}

The fracture during both $700{ }^{\circ} \mathrm{C}$ pre-cracking and sustained load was fully intergranular, as exemplified for the latter in Figure 3(a). This is in agreement with previous observations in Allvac 718Plus with precipitate free grain boundaries [8]. In contrast, the room temperature pre-crack was transgranular, as illustrated in Figure 3(b). Occasionally, oxidation over some tenths of $\mu \mathrm{m}$ could be seen in intersections between slip bands and intergranular cracks. In no instance did such oxidation 
lead the crack to propagate along the slip band. Neither did sustained load crack growth occur in other boundaries or defects, such as annealing twin boundaries. In no instance did such oxidation lead the crack to propagate along the slip band. Figure 4 shows a region analysed by SIMS where locally plasticized areas, slip bands and also a twin boundary are all present in the intergranular crack flank. None of these features exhibit any increased levels of oxygen.

In Type 1 samples un-cracked ligaments were observed in the intergranular sustained load crack path, as shown in Figure 5(a). These ligaments frequently exhibited highly plasticized torch-like regions ahead of the intergranular cracks (as previously reported in [7, 24]). The SIMS map in Figure 5(b) shows that ${ }^{18} \mathrm{O}$ is strictly confined to the intergranular cracks on each side of the un-cracked ligament. Detailed studies of the microchemistry by APT reveal that neither the ligaments in general nor the torch-like regions exhibit any increased levels of oxygen compared to the as-received material, see Table 2.

After completed investigations of the cross-sections, the specimens were fractured by bending at room temperature. Figure 6(a) shows a stereo-optical image of (half) the specimen fracture surface of a Type 1 specimen. The starting notch can be seen at the bottom of the image, and the period of high temperature testing can be clearly distinguished by its dark blue surface oxide. The intergranular fracture is exemplified in Figure 6(b), and the transition from room temperature to high temperature pre-cracking can be clearly seen in Figure 6(c). The crack front is curved due to so-called "crack tunnelling", where the constraints, which depend on the stress state, are different at the surface and in the specimen interior [29]. Such behaviour is generally more pronounced under conditions resulting in intergranular cracking [30], although in the present case the curvature of the crack front was similar after RT pre-cracking and SLCG.

As the fracture surfaces from both high temperature pre-cracking and SLCG are intergranular and could not be separated from the oxide colour, it was necessary to transform the recorded PD data to crack lengths in order to identify position on the fracture surface were the sustained load period started. For this a calibration function $a=f(\mathrm{PD})$ must be used. The occurrence of complex crack geometries can lead to large deviations from the crack lengths predicted by experimental, numerical or analytical calibration curves unless the correct geometry is considered [31]. In addition, it has been shown that experimental calibration curves generated during fatigue loading are not necessarily valid for crack growth under creep-fatigue conditions [32]. To overcome these problems crack length measurements from the fractured specimens were used for calibration in the following manner: The crack lengths at the start and finish of high temperature testing (steps 3 and 4 in Figure 2(c) and Table 2) were measured based on the oxidized region of the fracture surface. Here the frontmost point on the crack front was used as a measure of the crack length, although in practice any definition of crack 
length could be used for comparative purposes as long as it is done consistently. The crack lengths were correlated to the recorded PD values at the start of the high temperature pre-cycling and the end of the sustained load period, and the crack length was assumed to be a linear function of PD, allowing $f$ to be calibrated from only these two measurements. This is a very good approximation over limited crack length intervals. Finite element simulations of the PD vs. $a$ response using the experimentally observed crack front geometries were carried out to verify this, and the error in crack length was smaller than $2.5 \%$ over the interval $3 \leq a \leq 5 \mathrm{~mm}$. Finally, the recorded PD signal during sustained load cracking was transformed to crack lengths using the linear calibration function. An example of the calculated crack length at the start of the sustained load period is shown for specimen 1B in Figure 6(a). This removes much of the uncertainty in the PD measurements, as the start and end-point of the high temperature testing are fixed for each individual specimen, and all crack lengths during sustained load cracking are simply interpolated. Note that in the present case the crack front geometry was relatively constant when comparing the start and finish of the high temperature test part.

Parts of the crack front, typically around $100 \mu \mathrm{m}$ in width, lag behind the leading parts. The lag is also in order of around $100 \mu \mathrm{m}$. This creates a jagged crack front, as has previously been reported in [4]. The reason for this is presumably the difference in resistance to sustained load cracking in adjacent grain boundaries. Figure 6(d) shows a drastic example of un-cracked "fingers" reaching back from the crack front. These "fingers" suffered ductile fracture in tension during breaking of the specimen, as is characteristic of all parts of the fracture surface created during the separation of the specimen halves by bending at room temperature. In specimen $2 \mathrm{~A}$ the un-evenness occurred on a significantly larger scale, both regarding amplitude and wavelength, giving a more wavy appearance (on which the small scale jaggedness is superposed), as shown in Figure 7. This could possibly be an indication of larger textured regions with more resistant microstructure.

Additionally, un-cracked ligaments, manifested as isolated islands of ductile fracture following bending at room temperature, were occasionally seen in the crack wake, as illustrated in Figure 6(e). They were consistently located within some $200 \mu \mathrm{m}$ from the crack front. However, very few such ligaments could be observed compared to what could be expected from the jagged crack front. Also, their positions close to the crack front indicate that the observed ligaments were formed during the later stages of crack growth. No regions exhibiting ductile fracture, indicative of ligaments fractured by creep or other more plastic fracture mechanisms, were observed further back in the crack wake.

\subsection{Final cycling of Type 2 specimens}

Figure 8 shows the very crack tip region in a Type 2 specimen, where the high temperature sustained load period ended and $10 \mathrm{~Hz}$ fatigue cycling in Argon at room temperature commenced after forced convection cooling (also in Argon). There is a clear transition from intergranular to transgranular 
fracture, where the SIMS map in Figure 8(b) shows that there is no ${ }^{18} \mathrm{O}$ in the frontmost transgranular part of the crack. In the Type 1 specimens, ${ }^{18} \mathrm{O}$ was consistently present all the way to the crack tip, verifying that oxygen could access the crack tip during sustained load, which is why the transganular part of the crack free of ${ }^{18} \mathrm{O}$ in Figure 8 must have been created during final cycling in Argon.

Occasionally ligaments, which had been left behind by the advancing crack front during the sustained load period, were found to have fractured by fatigue during the final room-temperature cycling. This is exemplified in Figure 9(a), where a fatigue crack, with the characteristic adjacent plasticity, has joined two brittle intergranular cracks (only one edge of the cracked ligament is included in the figure). The corresponding SIMS map in Figure 9(b) shows that ${ }^{18} \mathrm{O}$ is only present in the intergranular sustained load crack, proving that the ligament fracture has occurred after the end of the sustained load period. In agreement with the observations from the Type 1 specimens, the fractured ligament was found some $50 \mu \mathrm{m}$ behind the crack tip.

Investigations of the fracture surfaces support the observations from the cross-sections. A zone consisting mainly of striations caused by fatigue crack growth could be seen at the crack front, as illustrated in Figure 10(a). The zone was typically some 10-40 $\mu \mathrm{m}$ wide and primarily existed ahead of the leading parts of the intergranular sustained load crack front. Little evidence of crack propagation was found at the lagging parts, in spite of the much higher stress intensities expected compared to the leading parts.

The majority of the ligaments that could be observed in the crack wake exhibited dimples from ductile tearing. This indicates that they had fractured during the post-test separation of the specimen rather than during the cyclic load period of the test. Some instances of fatigue cracking could be observed, e.g. Figure 10(b), where a ligament has partially fractured during cyclic loading before ductile tearing of the remaining part.

\section{Discussion}

\subsection{Interaction between environment, microstructure and crack growth}

In the present investigation, neither plastically deformed zones at the crack flanks nor severely plasticized ligaments or crack tip regions showed any increase in oxygen levels. Both techniques employed for studying the local oxygen concentrations (APT and SIMS) have ppm sensitivity and the capability to distinguish isotopes. The NanoSIMS allows scans of regions several $\mu \mathrm{m}$ in size at a spatial resolution somewhat below $100 \mathrm{~nm}$, whilst APT is far more limited in its acquisition volume (typically bound to less than 500x50x50 nm), but with near-atomic resolution in three dimensions. The ease of compositional quantification also differs between these particular instruments, where APT allows detailed and straightforward quantification of oxygen, in comparison to NanoSIMS. By 
combining these techniques, however, both overview and details on the distribution of ${ }^{18} \mathrm{O}$ could be studied. This approach ascertained that the present findings of no $\mu \mathrm{m}$-scale distribution of oxygen in the plastically deformed regions (NanoSIMS), or atomic-scale local elevated concentrations of oxygen in the same regions (APT) are truly valid. The one uncertainty remaining is whether or not oxygen can penetrate the material on a scale below the spatial resolution of the SIMS or the spatial accuracy of APT sample preparation (here some hundreds of nanometres). However, recent TEM investigations by Kitaguchi et al. [13], however, did not indicate any oxygen diffusion on that scale beneath the oxide.

The un-cracked ligaments formed during SLCG are assumed to be created by the three-dimensional percolation of the crack front along less resistant high-energy grain boundaries, leaving stronger boundaries intact in the wake. It is well known that grain boundary diffusivity is affected by the nature of the boundaries (symmetry, orientation, etc) and this has been shown to affect the susceptibility for cracking of Alloy 718 bi-crystals under sustained load conditions [19, 33]. Such reasoning is also consistent with findings by Krupp et al. $[17,18]$ on polycrystalline Alloy 718 under constant displacement conditions at $650{ }^{\circ} \mathrm{C}$. It was shown that an increased fraction of special boundaries, and in particular $\Sigma 3$ boundaries, increases the resistance towards fracture. The increased fraction of these special boundaries was correlated to an increased amount of un-cracked ligaments. Recent work by Unocic et al. [20] also shows an increased fraction of $\Sigma 3$ grain boundaries in Allvac 718Plus to increase resistance for cracking, however, no results regarding ligaments were presented.

In the present work, only a small number of ligaments were found in the crack wake and these were located close to the position of the crack front when the sustained load was interrupted. This is in contrast to previous studies [16-18], where islands of ductile fracture were found throughout the crack wake. The low number of ligaments could be explained by the precipitate free grain boundary condition, known to provide less resistance to SLCG [8]. The highly intergranular crack path suggests that the vast majority of the lagging parts of the crack front will fracture through the same embrittlement mechanism as the leading parts. The present work also clarifies that the un-cracked ligaments near the crack front are not affected by oxygen during the sustained loading. It is however likely that given time the ligaments will eventually suffer oxygen-induced fracture. Therefore, it is plausable that ligaments have indeed been left in the crack wake throughout the SLCG, but they have continuously fractured in a brittle manner as the loading increased due to the increasing crack length. This is in contrast to the proposed mechanism of ligament failure through creep, which would leave islands of ductile fracture, as suggested for alloys with more crack resistant grain boundaries [4]. As has been shown, not even the most resistant boundaries are fully immune to cracking, but they do require higher stress intensities to initiate crack growth [19]. 
As discussed above, the present study shows no diffusion of oxygen at $\mu \mathrm{m}$-scale in the region ahead of, or around, the crack tip. Furthermore, it has previously been shown that oxidation of the grain boundary region occurs over approximately $1 \mu \mathrm{m}$ ahead of the crack tip [14]. The fact that the interaction between the material and the oxygen occurs over such limited distances also indicates that the crack growth during final cyclic loading at room-temperature, which occurs over some 10 to 40 $\mu \mathrm{m}$ in this study, should be un-affected by any oxygen induced damage. The cyclic crack growth mainly occurred at the leading parts of the jagged crack front, rather than at the lagging parts, that could have been expected to crack rapidly due to the higher local stress intensities. Given that the oxygen related damage is very local, and that room temperature fatigue crack growth occurred transgranularly during pre-cracking, it is difficult to imagine that the nature of the resistant grain boundaries should exert such large influence during final cycling. A more likely explanation is that plastic deformation during the sustained load will act in a similar fashion as a tensile overload during the subsequent cycling, creating a zone of compressive stress ahead of the crack. The larger plastic strains at the lagging parts, relative to the leading parts, will be more effective in hindering fatigue crack growth.

\subsection{Effects of ligaments on crack tip loading}

The detailed effect of the un-cracked ligaments and local main crack front geometry on SLCG is still to be fully investigated. In the work by Pfaendtner et al. [4] the ligaments are considered to be capable of bearing large portions of the applied load. The ligaments may thus hinder crack growth by reducing strain/stress localization in the crack tip region and consequently prevent fracture of the brittle cracktip oxide and/or reduce strain/stress enhanced oxygen penetration and/or oxidation.

To investigate the effects of crack front geometry on the crack tip loading condition, finite element (FE) simulation was used. The model (schematically shown in Figure 11(a)) was set up in COMSOL ${ }^{\circledR}$ Multiphysics software, and consisted of one quarter of the specimen given symmetries. Four crack geometries, schematically shown in Figure 11(b)-(e), were simulated, corresponding to: (b) straight crack front with no ligaments in the wake; (c) straight crack front with eight ligaments (for the full specimen width) in the wake, with a radius of $25 \mu \mathrm{m}$ and with their centre located $100 \mu \mathrm{m}$ behind the crack front; (d) jagged crack front (represented by semi-circular intrusions and protrusion from the crack front), with wavelength $100 \mu \mathrm{m}$ and amplitude $50 \mu \mathrm{m}$; (e) Wavy crack front (represented by a sine wave) with wavelength $1.5 \mathrm{~mm}$ and amplitude $125 \mu \mathrm{m}$, based on findings such as those in Figure 7. In all cases the frontmost part(s) of the crack was located at $3.5 \mathrm{~mm}$. To investigate the limiting case, i.e. maximum shielding effects, a linear elastic material model was used, since plastic deformation of the shielding features (ligaments and lagging parts) will lead to a smaller effect. The elastic material constants were set to $E=200 \mathrm{GPa}$ and $v=0.3$, however their actual values are not 
important since it is the relative effects that are subject to study here. The specimen was loaded to 125 $\mathrm{MPa}$ in tension, and the resulting normal stresses ahead of the tip $\left(\sigma_{\mathrm{zz}}\right)$ were extracted. The calculated normal stresses are shown in Figure 12(a), and their relative values (i.e. divided by the results from simulations with straight crack front without ligaments) are shown in Figure 12(b).

Although the results must be viewed as qualitative, it is clear that the presence of ligaments and local crack front geometry could have a substantial effect on the stress and strain conditions at the crack tip. In the present case, the ligaments do not yield a marked effect simply due to their low number, which in turn is believed to be related to the very brittle fracture owing to the lack of grain boundary phases. The very high stresses at and around the ligaments will lead to substantial plastic deformation of the ligaments, causing further reductions in the calculated shielding effects. In materials with a larger portion of ligaments, such as in $[17,18]$ where area fractions of 5-10\% were observed, they can impose much greater effect on the overall crack growth rates. In cases such as the present one, the wavy and jagged nature of the crack front plays a much greater role for reducing the crack tip loading with a smaller wavelength providing more effective shielding. The effect of reduced crack tip stresses on the driving force for crack growth will be further amplified by the fact that the crack growth rate is generally proportional to the stress intensity factor raised to the power of 3-4. The present simulations do not allow proper extraction of near tip stress fields and reductions in stress intensity, and without including plasticity effects the values must not be taken as realistic estimates. Nevertheless, the analysis illustrates the possible effects of geometry on the crack growth rate.

\section{Conclusions}

The high-temperature sustained load crack growth in Ni-base superalloy Allvac 718Plus was investigated using a combination of mechanical testing in controlled atmosphere, fractographical and microanalytical investigations, and finite element modelling. To emphasize the environmental effect, the material was heat-treated to remove all grain boundary precipitates otherwise present from industrial heat treatments.

The crack front after the sustained load period is un-even on two scales: jaggedness on the scale of $100 \mu \mathrm{m}$ is observed in all specimens, whereas mm-scale waviness could occasionally be observed. The jaggedness can be explained by a percolation-type crack growth along weaker grain boundaries, whereas the large-scale waviness is presumably due to larger textured regions with higher crack growth resistance. The un-even crack front can potentially have substantial effects on the loading conditions at the crack tip, which has not been considered in detail in previous treatments of oxygen assisted cracking. 
In the wake of the crack front ligaments of un-broken material were found as a result of the crack percolation. In the present case the ligaments fail in an intergranular manner rather than by creep deformation as previously proposed. Due to their low number, their effect on the crack tip stress field is predicted to be minor in the present case. Applying cyclic loading at room temperature, after the sustained load period, causes fatigue crack growth to occur primarily at the leading parts of the crack front, rather than the lagging parts, in spite of the lower stresses. Also the ligaments fracture during cyclic loading but not at a rate lower than expected.

In addition, no measurable $\mu \mathrm{m}$-scale diffusion of oxygen could be observed in the plastically deformed regions around the crack tip or ligaments, confirming that the effect oxygen on the cracking process takes place on a very local scale.

\section{Acknowledgements}

The authors are grateful to Professor Chris Grovenor at the Department of Materials, Oxford University, for collaboration and access to the NanoSIMS instrument. Also, collaborators at SwereaKIMAB (Stockholm, Sweden) are thanked for devising the controlled environment test rig and for the joint effort of mechanical testing. The work was performed within the Swedish High-Temperature Corrosion Centre and was also supported by the Swedish Governmental Agency for Innovation Systems (VINNOVA) through the National Aeronautical Research Program (NFFP) and the Swedish Foundation for Strategic Research (SSF) through the Strategic Mobility Program.

\section{References}

[1] E. Andrieu, R. Molins, H. Ghonem, A. Pineau, Mater. Sci. Eng. A, 154 (1992) 21-28.

[2] H. Ghonem, D. Zheng, Mater. Sci. Eng. A, 150 (1992) 151-160.

[3] R. Molins, G. Hochstetter, J.C. Chassaigne, E. Andrieu, Acta Mater. 45 (1997) 663-674.

[4] J.A. Pfaendtner, C.J. McMahon, Acta Mater. 49 (2001) 3369-3377.

[5] U. Krupp, W.M. Kane, C. Laird, C.J. McMahon, Mater. Sci. Eng. A 387-389 (2004) 409-413.

[6] M. Hörnqvist, L. Viskari, K. Stiller, G. Sjöberg, in: E.A. Ott, J.R. Groh, A. Banik, I. Dempster, T.P. Gabb, R. Helmink, X. Liu, A. Mitchell, G.P. Sjöberg, A. Wusatiwska-Sarnek (Eds.), 7th International Symposium on Superalloy 718 and Derivatives, TMS, Pittsburgh, PA, 2010, pp. 705717.

[7] D. Gustafsson, J.J. Moverare, S. Johansson, K. Simonsson, M. Hörnqvist, T. Månsson, S. Sjöström, Int. J. Fatigue 33 (2011) 1461-1469.

[8] L. Viskari, Y. Cao, M. Norell, G. Sjöberg, K. Stiller, Mater. Sci. Eng. A 528 (2011) 2570-2580.

[9] U. Krupp, Int. Mat. Rev. 50 (2005) 83-97.

[10] D.A. Woodford, Energy Mater. 1 (2006) 59-79. 
[11] A. Pineau, S.D. Antolovich, Eng. Fail. Analysis 16 (2009) 2668-2697.

[12] R.H. Bricknell, D.A. Woodford, Metall. Mater. Trans. 12A (1981) 1673-1680.

[13] H.S. Kitaguchi, H.Y. Li, H.E. Evans, R.G. Ding, I.P. Jones, G. Baxter, P. Bowen, Acta Materialia, 61 (2013) 1968-1981.

[14] L. Viskari, M. Hörnqvist, K.L. Moore, Y. Cao, K. Stiller, Acta Mater. 61 (2013) 3630-3639.

[15] H.E. Evans, H.Y. Li, P. Bowen, Scripta Mater., 69 (2013) 179-182.

[16] D. Bika, J.A. Pfaendtner, M. Menyhard, J. McMahon C.J, Acta Metall. Mater. 43 (1995) 18951908.

[17] U. Krupp, W.M. Kane, X. Liu, O. Dueber, C. Laird, C.J. McMahon Jr, Mater. Sci. Eng. A, 349 (2003) 213-217.

[18] U. Krupp, P.E.G. Wagenhuber, W.M. Kane, C.J. McMahon Jr, Mater. Sci. Tech. 21 (2005) 12471254.

[19] W.M. Kane, C.J. McMahon Jr, Mater. Sci. Eng. A, 507 (2009) 61-65.

[20] K.A. Unocic, R.W. Hayes, M.J. Mills, G.S. Daehn, Metall. Mater. Trans. 41A (2010) 409-420.

[21] D. Gustafsson, J. Moverare, K. Simonsson, S. Johansson, M. Hörnqvist, T. Månsson, S. Sjöström, Procedia Eng. 10 (2011) 2821-2826.

[22] D. Gustafsson, E. Lundström, Int. J. Fatigue 48 (2013) 178-186.

[23] D. Gustafsson, E. Lundström, K. Simonsson, Int. J. Fatigue 52 (2013) 124-130.

[24] L. Viskari, S. Johansson, K. Stiller, Mater. High Temp. 28 (2011) 336-341.

[25] D. Zheng, A. Rosenberger, H. Ghonem, Mater. Sci. Eng. A 161 (1993) 13-21.

[26] S. Lozano-Perez, M.R. Kilburn, T. Yamada, T. Terachi, C.A. English, C.R.M. Grovenor, J. of Nuclear Mater. 374 (2008) 61-68.

[27] M. Sennour, L. Marchetti, F. Martin, S. Perrin, R. Molins, M. Pijolat, J. of Nuclear Mater. 402 (2010) 147-156.

[28] J.J. Moverare, S. Johansson, R.C. Reed, Acta Mater. 57 (2009) 2266-2276.

[29] F.V. Antunes, J.M. Ferreira, C.M. Branco, J. Byrne, Fatigue Fract. Eng. Mater. Structures 24 (2001) 127-135.

[30] M.R. Bache, W.J. Evans, M.C. Hardy, Int. J. Fatigue 21 (1999) S69-S77.

[31] F.O. Riemelmoser, R. Pippan, H. Weinhandl, O. Kolednik, J. Test. Eval. 27 (1999) 42-26.

[32] N. Merah, J. Test. Eval., 28 (2000) 301-306.

[33] W.M. Kane, U. Krupp, C.J. McMahon Jr, Mater. Sci. Eng. A 507 (2009) 58-60. 
Table 1. Nominal composition of the Allvac 718Plus alloy (wt. \%).

\begin{tabular}{|l|l|l|l|l|l|l|l|l|l|l|l|l|}
\hline Element & $\mathrm{Ni}$ & $\mathrm{Cr}$ & $\mathrm{Fe}$ & $\mathrm{Co}$ & $\mathrm{Nb}$ & $\mathrm{Mo}$ & $\mathrm{Al}$ & $\mathrm{W}$ & $\mathrm{Ti}$ & $\mathrm{C}$ & $\mathrm{P}$ & $\mathrm{B}$ \\
\hline Wt. \% & Bal. & 18 & 9.5 & 9.1 & 5.4 & 2.7 & 1.45 & 1.0 & 0.75 & 0.02 & 0.006 & 0.005 \\
\hline
\end{tabular}

Table 2. Summary of the applied loading conditions in the different test steps. The numbered steps refer to Figure 2(c).

\begin{tabular}{|l|l|l|l|}
\hline Step & Temperature & Environment & Loading \\
\hline 1 & $20{ }^{\circ} \mathrm{C}$ & Air & $\begin{array}{l}\text { Cyclic loading, } 10 \mathrm{~Hz}, \mathrm{R}=0.05 \\
\text { Load level reduced in steps }\end{array}$ \\
\hline 2 & Heating & Air & Zero load, induction heating $20{ }^{\circ} \mathrm{C} \mathrm{s}^{-1}$ \\
\hline 3 & $700{ }^{\circ} \mathrm{C}$ & Air & $\begin{array}{l}\text { Cyclic loading, } 10 \mathrm{~Hz}, \mathrm{R}=0.05 \\
\text { Load level reduced in steps, } \\
\text { final maximum load } \mathrm{P}_{\max }=3 \mathrm{kN}\end{array}$ \\
\hline 4 & $700{ }^{\circ} \mathrm{C}$ & ${ }^{16} \mathrm{O}:{ }^{18} \mathrm{O}=1: 1$ & $\begin{array}{l}\text { Sustained tensile load at } 3 \mathrm{kN}(125 \mathrm{Mpa}) \\
\text { Oxygen mixture flow rate } 50 \mathrm{ml} \mathrm{s}{ }^{-1} \text { at } 2 \mathrm{bar}\end{array}$ \\
\hline 5 & Cooling & Argon & $\begin{array}{l}\text { Zero load, forced convection cooling } \\
\text { Argon flow rate } 500 \mathrm{ml} \mathrm{s}{ }^{-1} \text { at } 2 \text { bar }\end{array}$ \\
\hline $6{ }^{1}$ & $20{ }^{\circ} \mathrm{C}$ & Argon & $\begin{array}{l}\text { Cyclic loading, } 10 \mathrm{~Hz}, \mathrm{R}=0.05 \\
\text { Argon flow rate } 500 \mathrm{ml} \mathrm{s}{ }^{-1} \text { at } 2 \text { bar }\end{array}$ \\
\hline
\end{tabular}

${ }^{1}$ Type 2 only

Table 3. APT results showing oxygen content (at.\%) in the as-received material and in selected regions in tested material

\begin{tabular}{|l|l|l|l|}
\hline Region & As-received material & Torch-shape deformation & Un-cracked Ligament \\
\hline Oxygen $^{1}$ (at. \%) & $0.03 \pm<0.01$ & $0.02 \pm<0.01$ & $0.01 \pm<0.01$ \\
\hline
\end{tabular}

${ }^{118} \mathrm{O}+{ }^{16} \mathrm{O}$ 


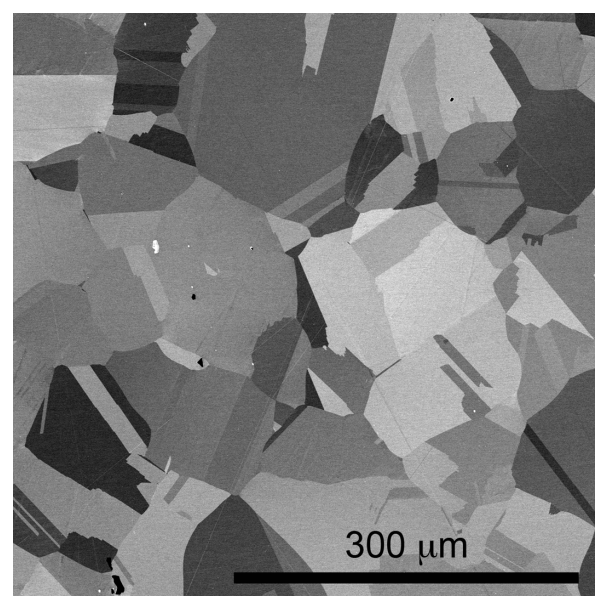

Figure 1. SEM image of the investigated microstructure of Allvac 718Plus. The grain boundaries are free of precipitates. Extensive twinning from heat treatment is clearly visible, as are some $\mathrm{Nb}$ and $\mathrm{Ti}$ carbides (bright and dark, respectively).

(a)
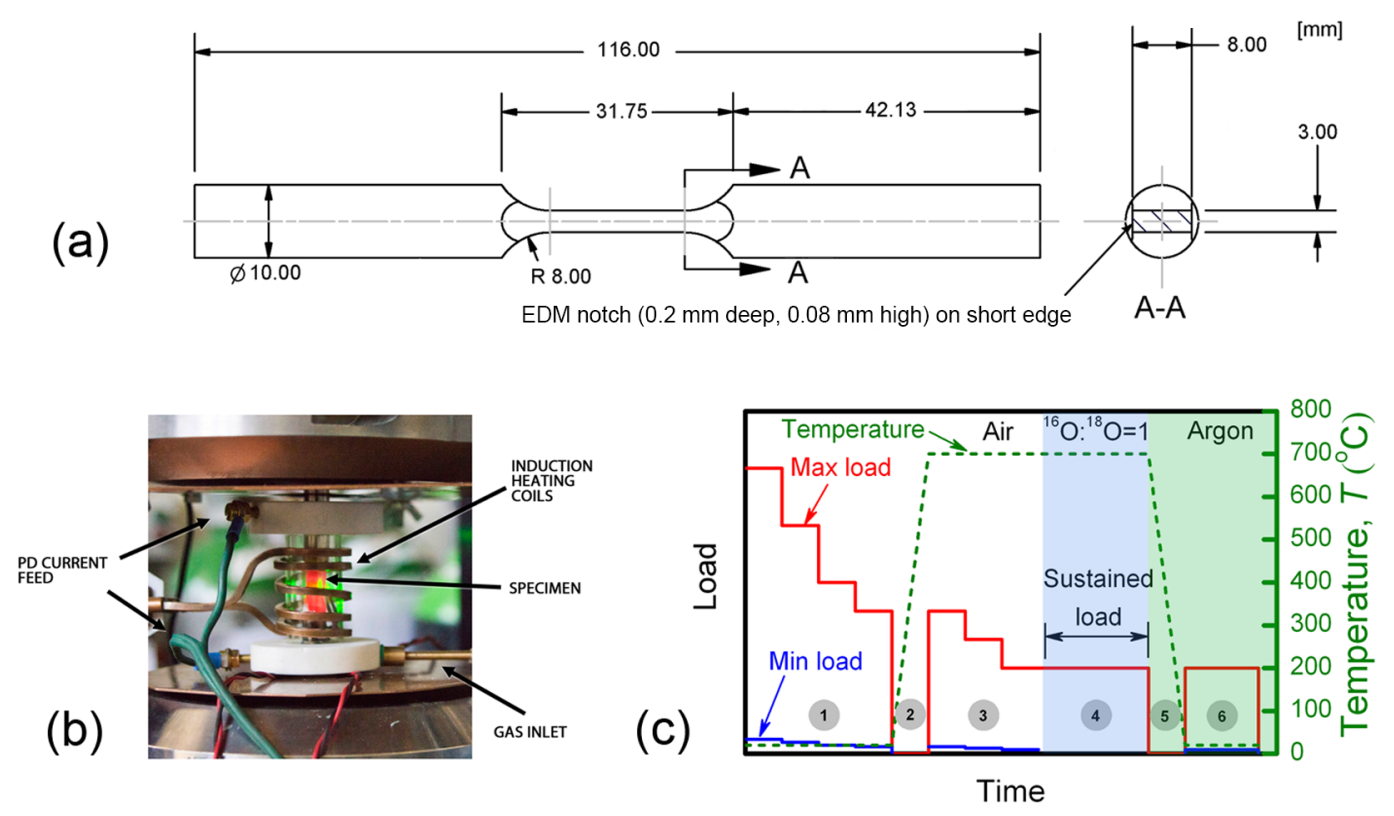

Figure 2. (a) Geometry of the single-edge notched test specimen. (b) Photograph of test set-up with the glowing specimen enclosed in a quartz tube to allow controlled atmosphere. (c) Schematic of applied load and temperature vs. time, showing the sequence of room temperature and high temperature fatigue pre-cracking, sustained load and final room temperature fatigue cycling (Type 2 specimens only). See Table 2 and text for further details. 

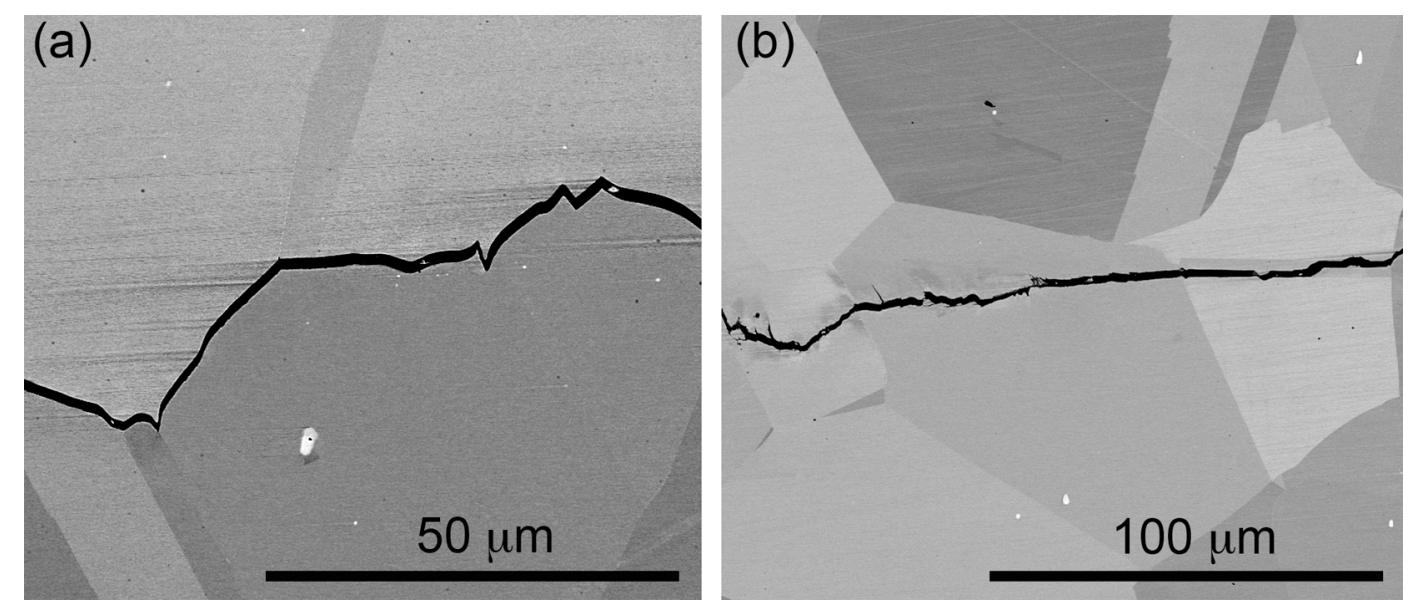

Figure 3. (a) Intergranular crack propagation during sustained load, and (b) transgranular room temperature fatigue cracking.
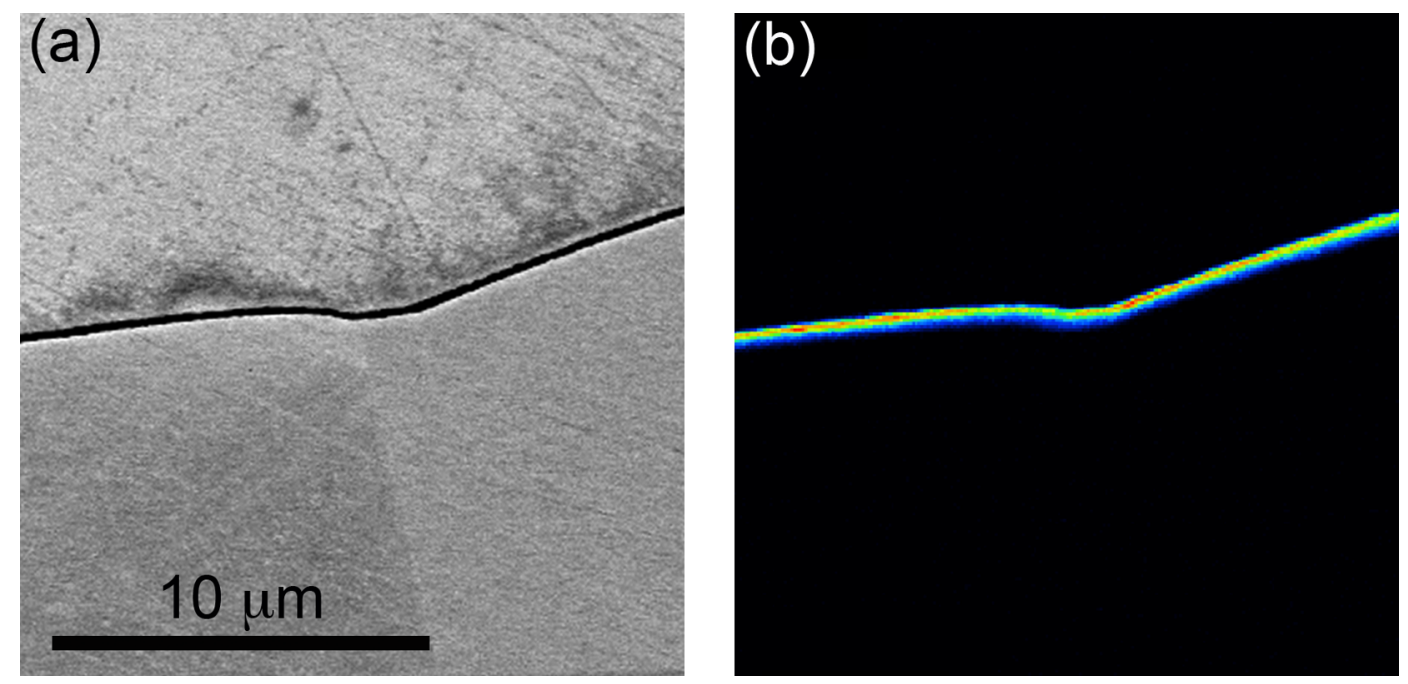

Figure 4. (a) BSE image of a sustained load crack, including plasticized regions and a twin boundary. (b) SIMS ${ }^{18} \mathrm{O}$ map of the same region showing the confinement of oxygen to the crack. 

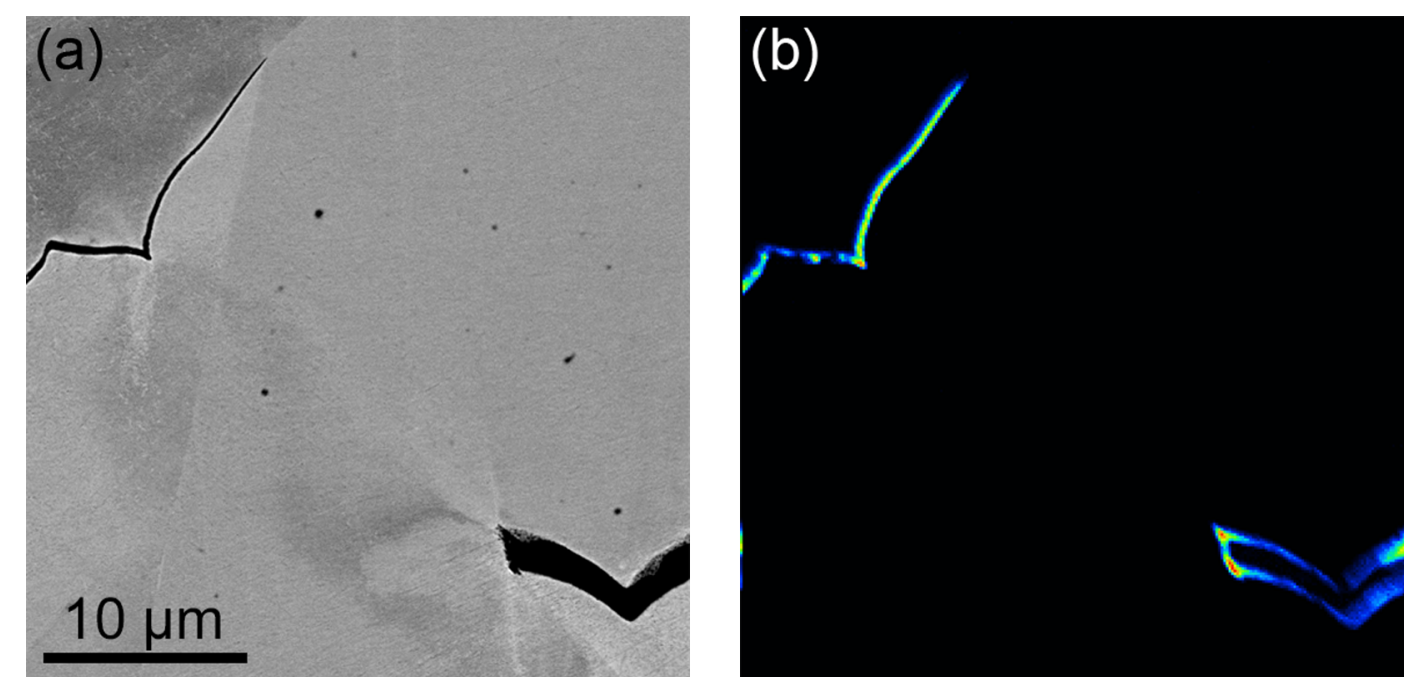

Figure 5. (a) BSE image of an un-cracked ligament in the crack wake, showing extensive localized plasticity. (b) ${ }^{18} \mathrm{O}$ map of the same region showing the absence of oxygen in the plasticized ligament.

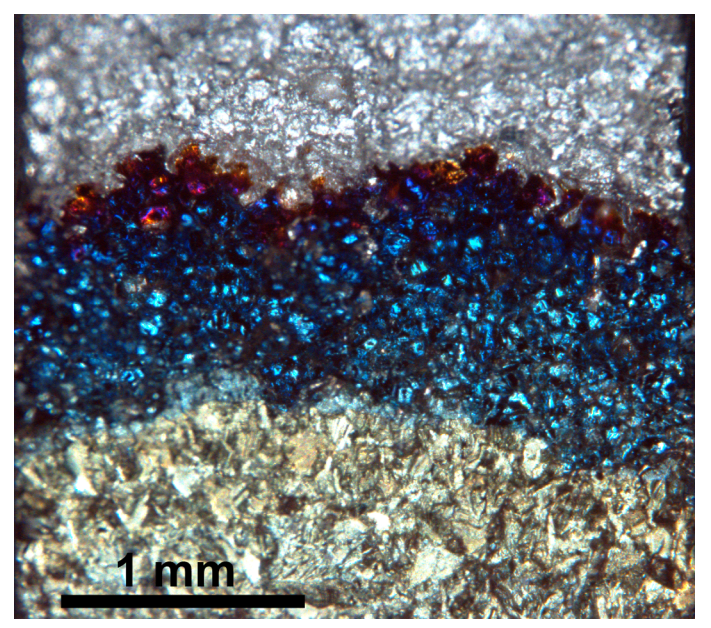

Figure 6. (a) Stereo-optical image of (one half) of the fracture surface from specimen 1B. The region corresponding to high temperature crack growth can be clearly seen from the surface oxidation. The dotted white line indicates the approximate start of the sustained load period calculated from the PD signal (see text for details). (b) Example of the intergranular fracture surface. (c) Boundary between room temperature and high temperature pre-crack, showing the transition from transgranular to intergranular crack growth. (d) Boundary between the sustained load crack and ductile fracture from post-test specimen fracturing at room temperature. (e) Fractured ligament in the crack wake. 


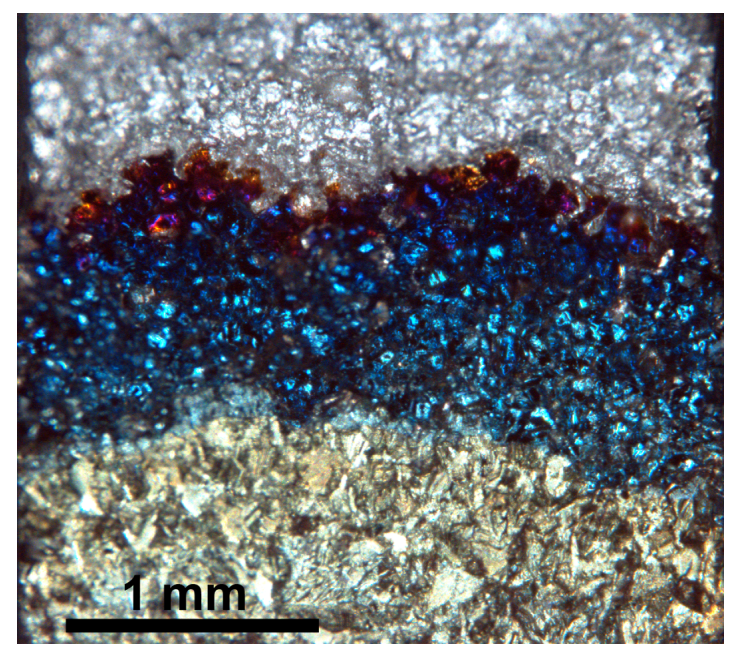

Figure 7. Fracture surface from specimen $2 \mathrm{~A}$, showing waviness of the crack front on mm scale, on which a jagged structure on the scale of around $100 \mu \mathrm{m}$ is superposed.
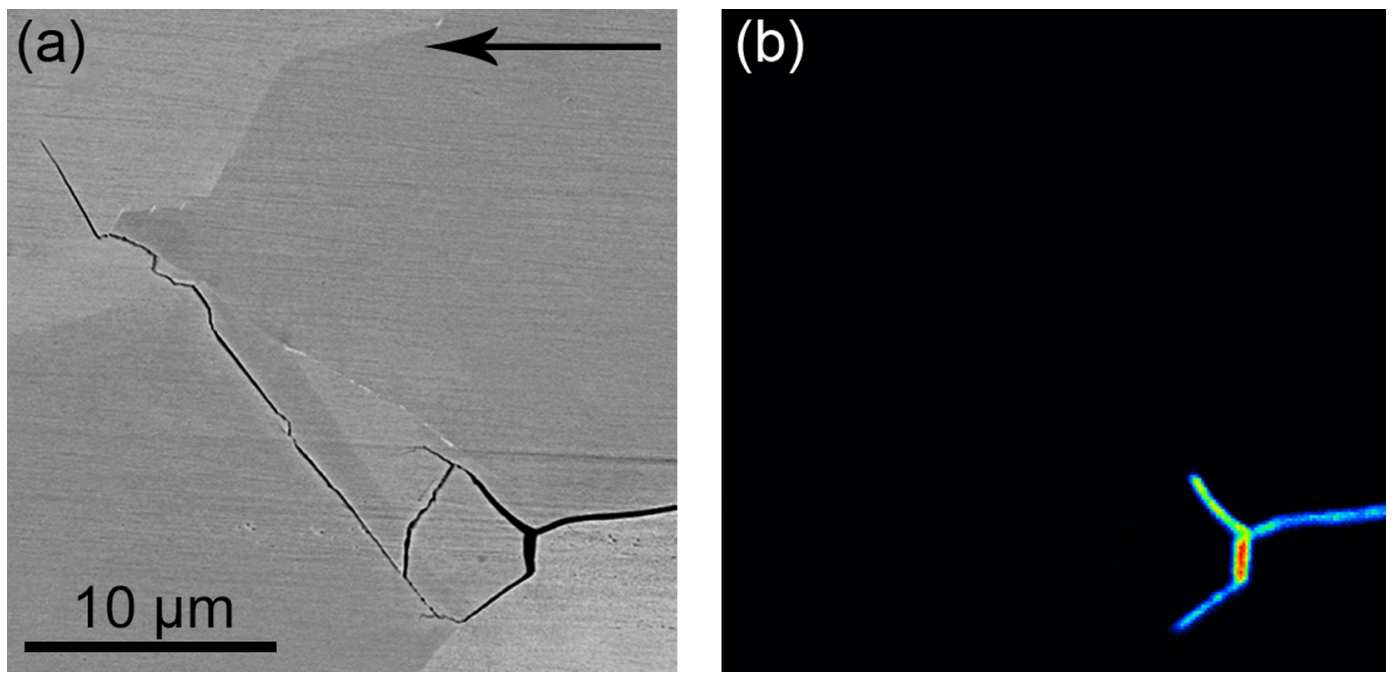

Figure 8. (a) BSE image of the very crack tip in specimen 2A, showing the transition from intergranular to transgranular fracture during the final room temperature fatigue cycling. (b) SIMS ${ }^{18} \mathrm{O}$ map of the same region indicating the absence of oxygen from the sustained load period ahead of the crack. The arrow indicates the direction of macroscopic crack growth. 

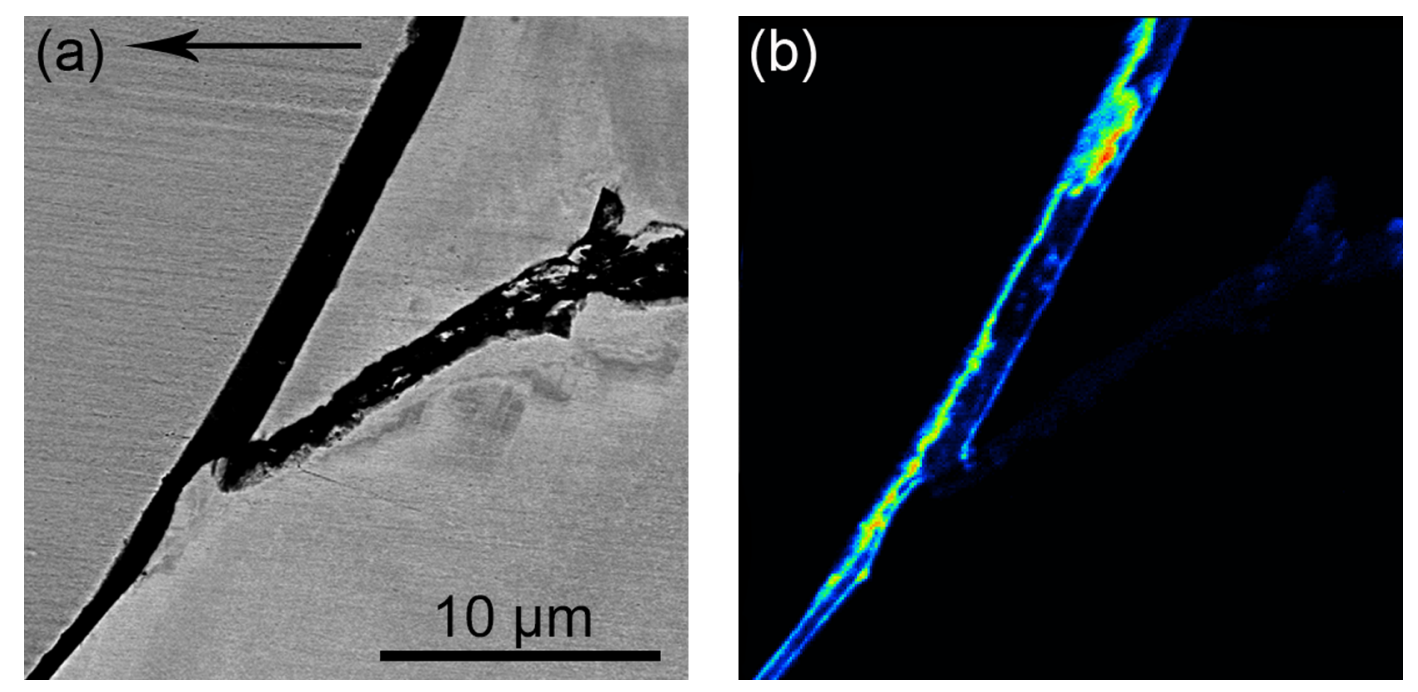

Figure 9. (a) BSE image of an un-cracked ligament from the sustained load cracking, which failed by fatigue during the final room temperature cycling. (b) SIMS ${ }^{18} \mathrm{O}$ map of the same region showing the presence of ${ }^{18} \mathrm{O}$ in the sustained load crack but not in the fatigue crack. The arrow indicates the direction of macroscopic crack growth.
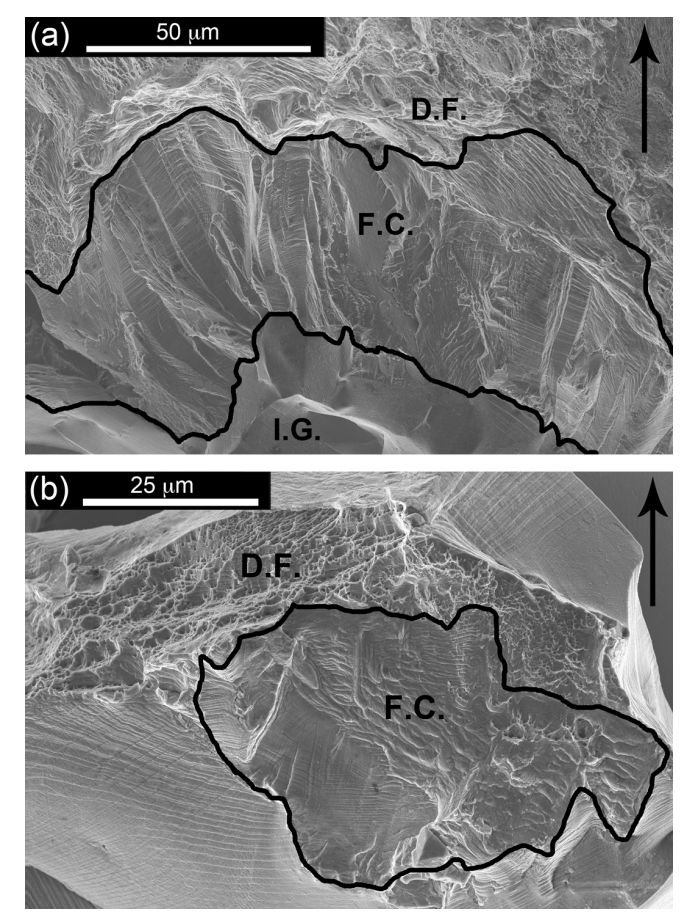

Figure 10. Images of the fracture surface of a specimen subjected to RT fatigue cycles in Ar after the sustained load. (a) The crack tip region showing intergranular fracture (I.G.) from the sustained load, fatigue crack growth (F.C.) over some 30-40 um, and ductile failure (D.F.) from breaking of the specimen. (b) Ligament in the crack wake, which has partly failed during RT fatigue. The remaining ligament suffered ductile failure during fracturing of the specimen. The arrows indicate the direction of macroscopic crack growth. 


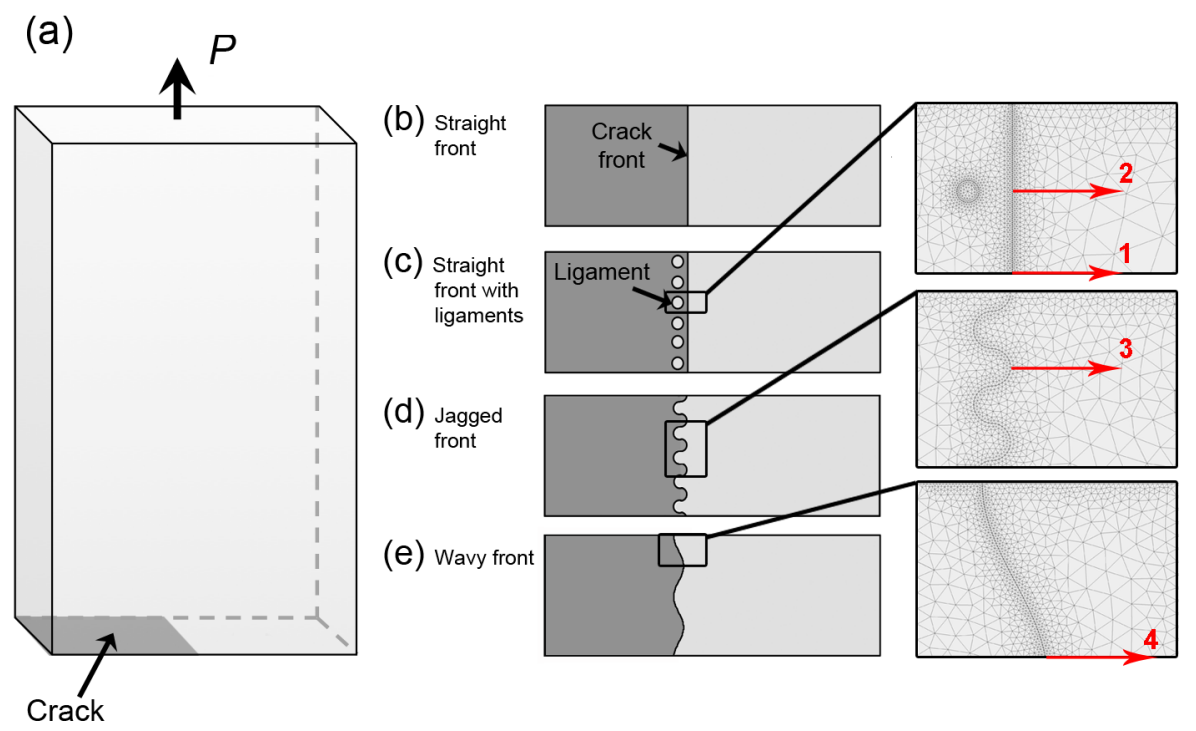

Figure 11. (a) Schematic drawing of the specimen geometry used for FE simulations. (b)-(e)

Schematic drawing of the crack plane with straight crack front, ligaments in the crack wake, jagged and wavy crack front, respectively (see text for more details). The full width of the cross-section (3x8 $\mathrm{mm})$ is shown in (b)-(e), whereas only half $(1.5 \times 8)$ was used in the simulations given symmetry. Close-ups of the FE meshes are shown for case (c) to (e). The numbered arrows indicate where the normal stresses in Figure 12 were extracted.
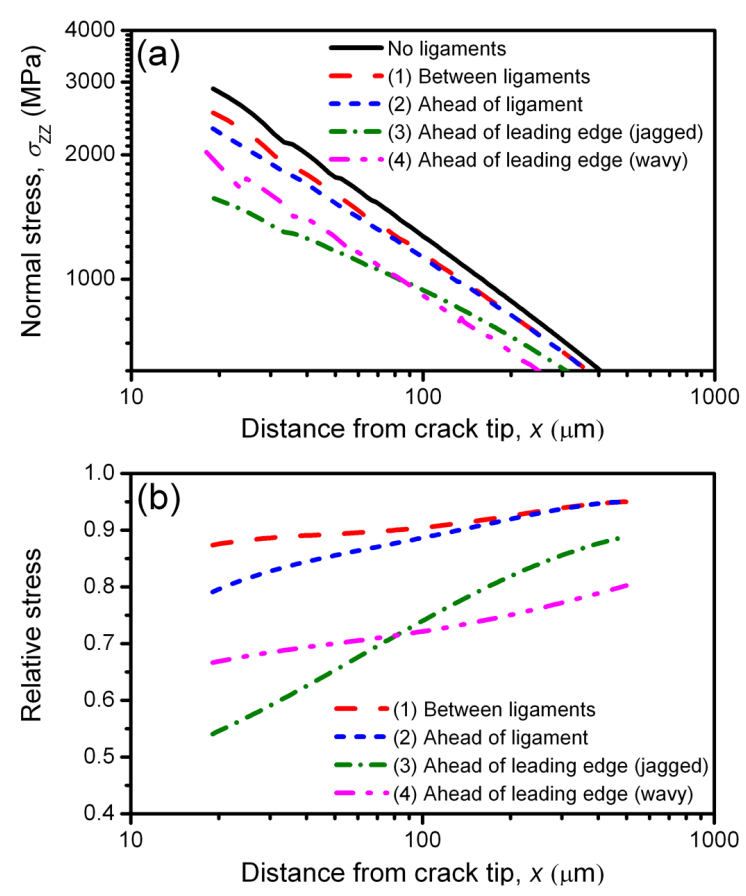

Figure 12. Results from the FE-simulations: (a) Stress distribution ahead of the crack; (b) Relative stresses ahead of the crack tip, expressed in terms of fractions of the case without ligaments. The numbers in the legend indicate the position as defined in Fig. 11. 